\title{
Surface Finish of Ball-End Milled Microchannels
}

\author{
D. Berestovskyi ${ }^{1}$ and W.N.P. Hung ${ }^{2}$ \\ ${ }^{1}$ Texas A\&M University, USA; d.berestovskiy@gmail.com \\ ${ }^{2}$ Texas A\&M University, USA; hung@tamu.edu
}

Key Words: micromilling, surface finish, biocompatible materials, minimum quantity lubrication, electrochemical polishing.

\begin{abstract}
This study develops micromanufacturing techniques to fabricate extremely smooth surface finish, high aspect ratio, and complex microchannel patterns. Computer controlled micromilling on a high speed machine system with minimum quantity lubrication is used to remove most materials and define a channel pattern. Assessment of microchannel is performed with optical microscopy, scanning electron microscopy, atomic force microscopy, and white light interferometry. Meso-scale milling confirms the validity of theoretical surface finish of ball-end milling, but surface finish in micro-scale milling is measured to be few orders of magnitude higher. Build-up-edge is reduced with optimally coated tool and milling in minimum quantity lubrication. The surfaces of milled microchannels are then further enhanced by subsequent electrochemical polishing process. When applying to 304, 316L stainless steel alloys and NiTi alloy, this hybrid technique can repeatedly produce microchannels with average surface finish in the range of 100-300 nm.
\end{abstract}

\section{A. INTRODUCTION}

Manufacturing of medical devices requires utmost precision and state-of-the-art quality control. Fluidic microdevices require small channels to transport precise doses of medicine or an exact amount of liquid to prescribed locations. Fabrication of microchannels on biocompatible materials is still a challenge when high aspect ratio, anisotropic profile, submicron surface finish, and controlled contour of the channel surface are required. Currently, manufacturing techniques such as laser machining and chemical etching are used to produce similar type of microchannels. However, laser can only produce microchannels with a flat bottom surface and an isotropic chemical etching process cannot produce high aspect ratio channels. In addition, chemical etching requires utilization of unique chemical solution for each material. This makes the process complex and time consuming. Conventional micromilling and microdrilling have the potential to be the most cost effective and efficient material removal processes. Depending on a system, micromilling could provide reasonable surface roughness, dimensional and geometric accuracy, and higher productivity comparing to other micromachining techniques. Also, different materials such as metal alloys, polymers, ceramics, and composites can be machined using the same milling cutters and setups [1]. However, conventional micromachining has much more challenges and constrains comparing to conventional macro machining. The challenges associated with micromachining rise from size effect of miniaturized cutting tools, work pieces, and overall process. When dimensions of a microtool and depth of cut are on the same order of magnitude as the grain size of the machined material, anisotropy of grain's mechanical properties and its crystallographic orientation influence the micro cutting process, which is not the case for the conventional macro cutting $[2,3]$. For micromachining the shear process at the tool tip is more complicated and depends on the degree of size effect, which is the effect observed when the depth of cut is about the same or smaller than cutting edge radius. In this case the rake angle has a high negative value, which leads to the serious increase in the shear force on the tool, surface roughness, elastic-plastic deformation, and the plowing during micromachining [4]. The plastic deformation of the machined surface results in more difficult separation of the material because material is work-hardened by increased dislocation density. Due to the large rake angle, the rise in the force results in a faster wear, an increase in the tool deflection and vibrations, and a build-up edge (BUE) formation on the micro tools $[4,5]$. Very often, failure of microtools occurs when chip thickness is smaller than cutting edge radius, which is about $3 \mu \mathrm{m}$ or larger for microtools [6]. Several researchers have studied the critical chip thickness. Vogler et al [7] utilized finite element analysis to find critical chip thickness for micromachining of steel. According to their study, the critical chip thickness can be estimated as $20-30 \%$ of the cutting edge radius during micromechanical machining of the pearlite and ferrite steel. However, Shimada et al [8] determined that critical chip thickness is about $5 \%$ of the tool edge radius during micromachining of aluminum and copper.

For microfluidic applications, surface finish of a channel is as important as the geometry of the channel profile. In a study of surface finish of micromilled cold worked SLD11 steel using TiAlN coated WC $\phi 900 \mu \mathrm{m}$ flat end mills, it was found that surface finish does not depend on feed as it does in conventional macromilling. The finish is not affected by axial depth of cut, but radial depth of cut has the most significant impact if there is any chattering [9]. Other authors [10] investigated the influence of the cutting fluid and cutting speed on the surface roughness during micro milling of Ti6Al4V with WC flat end mill. Surface finish rises with machined distance during dry cutting, but does not change 
significantly with machined distance when cutting fluid is used. Increasing cutting speed from $51 \mathrm{~m} / \mathrm{min}$ to $198 \mathrm{~m} / \mathrm{min}$ improves surface finish from $0.6 \mu \mathrm{m}_{\mathrm{z}}$ to $0.37 \mu \mathrm{m} \mathrm{R}_{\mathrm{z}}$. Similar conclusion was made in another study [11]. Surface finish of Ti-6Al-4V also improves with increasing milling speed, and the effect of speed is more significant than feed. Surface finish in micromilling contradicts with common experiences in macromilling that surface finish is a strong function of chip load or milling feed rate [12].

For microchannel fabrication, this research aims to (i) study surface finish of ball-end micromilling on biocompatible materials, and (ii) identify technique to enhance surface finish of milled microchannels.

\section{B. EXPERIMENTS}

The study used 0.5-2.0 mm sheets of commercially pure titanium, NiTi alloy, 316L stainless steel, and 304 stainless steel. All sheet samples (50 $\mathrm{mm}$ x $50 \mathrm{~mm}$ maximum) were cut by wire-type electrical discharge machining (wire EDM) rather than shearing to avoid possible bending of a sample. The thin sheets were glued to a larger aluminum block using a heat activated wax that melts at $75^{\circ} \mathrm{C}$. The base block and mounted sheet specimen were then secured on a milling table such that the sheet surface is parallel to the table plane within $0.005 \mathrm{~mm}$. All micromilling cutters were provided by Performance Micro Tools: Ø152-198 $\mu \mathrm{m}$ with spherical ends, 40-44 helix angle, 2 flutes, 200-300 $\mu \mathrm{m}$ flute length, and $\varnothing 3.175 \mathrm{~mm}$ shank. The tools were ground from solid WC-Co blanks with grain size at most $0.6 \mu \mathrm{m}$, sintered in $8 \%$ cobalt binder to 1900 Vicker hardness, $5.8 \mathrm{MPa}^{\mathrm{m}} \mathrm{m}^{0.5}$ toughness, 4.0 GPa transverse strength, and $590 \mathrm{GPa}$ modulus of elasticity. Some microtools were physical vapor deposited with AlTiN or the proprietary Nanotek coating by Swiss-Tek Coatings. Additional larger ball end mills of $\varnothing 3.175 \mathrm{~mm}$ with and without AlTiN coating were also used for comparison. These mesotools came with 4 flutes, $12.7 \mathrm{~mm}$ cutting length, and $38.1 \mathrm{~mm}$ total length. The Haas OM2 CNC system with $50,000 \mathrm{rpm}$ air bearing spindle was utilized for micromilling. The milling machine had a positioning accuracy of $\pm 5 \mu \mathrm{m}$ and repeatability accuracy of $\pm 3 \mu \mathrm{m}$. An $\varnothing 3.175 \mathrm{~mm}$ precision collet was used to mount and secure a microtool for minimal spindle runout.

The Keyence LKG-1577 laser displacement sensor was used for tool offset measurement. This noncontact laser technique provided precise tool offsets without compromising the process or deteriorated a fragile microtool. This laser system was also used to study tool and spindle runout. The laser sensor was connected to the data acquisition card DAC National Instruments NI USB-6008, which provided sampling rate $10 \mathrm{kHz}$. Setup of the tool runout measurements is shown in the Fig. 1. After mounting a new microtool in its collet and positioning a laser at its shank, runout data were collected using LabVIEW software for three different conditions:

i. Rotating spindle at $27238 \mathrm{rpm}$ without milling.

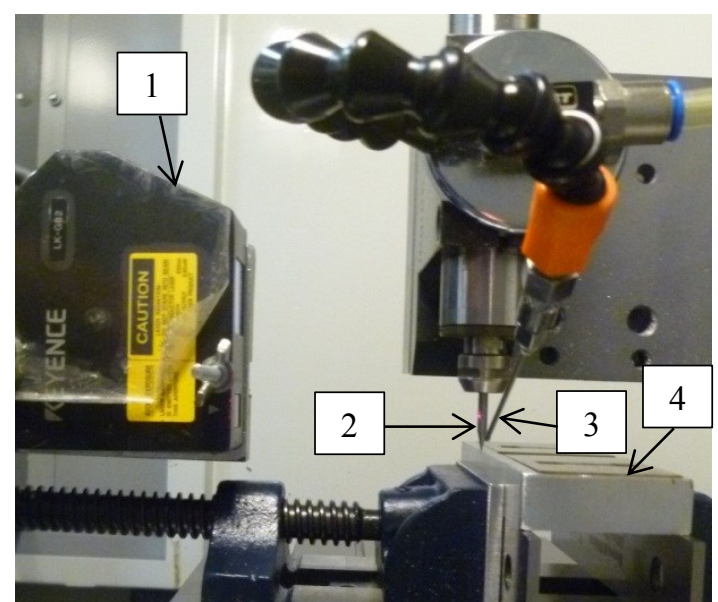

Fig. 1: Runout measurement setup using (1) Keyence laser, (2) micro ball end mill Ø $0.152 \mathrm{~mm}$, (3) micromist nozzle, and (4) workpiece

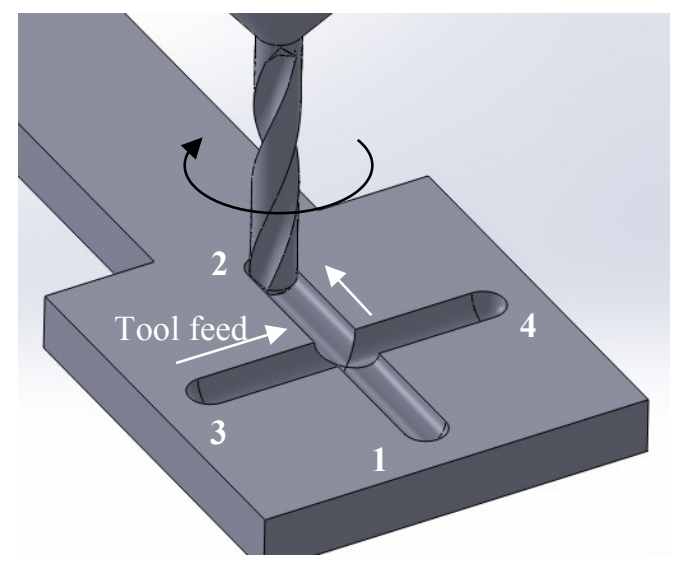

Fig. 2: Schematic representation of micromilling experiments. A tool starts at position \#1 and moves to \#2, lifts up and restarts at \#3 and \#4.

ii. Milling CP titanium at spindle speed $27238 \mathrm{rpm}$, feed rate $2.7 \mathrm{~mm} / \mathrm{min}$, depth of cut $0.038 \mathrm{~mm}$.

iii. Milling CP titanium at spindle speed $27238 \mathrm{rpm}$, feed rate $2.7 \mathrm{~mm} / \mathrm{min}$, depth of cut $0.076 \mathrm{~mm}$.

A Unist micromist system that produces minimum quantity lubrication (MQL) condition was integrated with the machine tool. The micromist nozzle tip was set to move with the tool. It was positioned $30 \mathrm{~mm}$ from the drill tip, $60^{\circ}$ from the spindle axis, $55^{\circ}$ from the $\mathrm{X}$-axis of milling machine, and delivered micromist from Coolube 2210EP lubricant.

Fig. 2 shows the schematic representation of micro milling experiments. Two perpendicular slots were milled on a specimen at particular cutting conditions. The slot length was set at $12 \mathrm{~mm}$ for 304 stainless steel and 316L stainless steel, and $8 \mathrm{~mm}$ for NiTi alloy. Each pair of cross slots was machined with a brand new tool. Tables 1-3 tabulate various milling parameters in this study. Although biocompatible materials like $\mathrm{CP} \mathrm{Ti}$, stainless steel, and NiTi are the primary focus of this research, other engineering materials like 6061-T6, and low carbon steel were also machined to complement surface finish data. 
Table 1: Cutting conditions for micromilling of NiTi alloy, $316 \mathrm{~L}$ and 304 stainless steels.

\begin{tabular}{l|c|c}
\hline Tool diameter $\varnothing[\mathrm{mm}]$ & 0.152 & 0.198 \\
\hline Coating layer & Uncoated & AlTiN \\
\hline Number of flutes & 2 \\
\hline Cutting speed $V[\mathrm{~m} / \mathrm{min}]$ & 24.0 \\
\hline Chip load $f_{t}[\mu \mathrm{m} /$ tooth $]$ & $0.05 ; 0.1 ; 0.2 ; 0.3$ \\
\hline Axial depth of cut $A_{p}[\mu \mathrm{m}]$ & 30 \\
\hline Cutting fluid & \multicolumn{2}{|c}{ Micromist } \\
\hline
\end{tabular}

Table 2: Cutting conditions for mesomilling of 6061-T6 aluminum alloy.

\begin{tabular}{|c|c|c|}
\hline Tool diameter $\varnothing[\mathrm{mm}]$ & \multicolumn{2}{|c|}{3.175} \\
\hline Coating layer & Uncoated & AlTiN \\
\hline Number of flutes & \multicolumn{2}{|c|}{4} \\
\hline Cutting speed $V[\mathrm{~m} / \mathrm{min}]$ & \multicolumn{2}{|c|}{60.0} \\
\hline Chip load $f_{t}[\mu \mathrm{m} /$ tooth $]$ & \multicolumn{2}{|c|}{$5 ; 10 ; 20 ; 30 ; 50 ; 80 ; 100$} \\
\hline Axial depth of cut $A_{p}[\mathrm{~mm}]$ & \multicolumn{2}{|c|}{0.05} \\
\hline Cutting fluid & \multicolumn{2}{|c|}{ Micromist } \\
\hline
\end{tabular}

Table 3: Cutting conditions for mesomilling of A36 low carbon steel.

\begin{tabular}{|c|c|c|}
\hline Tool diameter $\varnothing$ [mm] & \multicolumn{2}{|c|}{3.175} \\
\hline Coating layer & Uncoated & AlTiN \\
\hline Number of flutes & \multicolumn{2}{|c|}{4} \\
\hline Cutting speed $V[\mathrm{~m} / \mathrm{min}]$ & \multicolumn{2}{|c|}{30.0} \\
\hline Chip load $f_{t}[\mu \mathrm{m} /$ tooth $]$ & \multicolumn{2}{|c|}{$5 ; 15 ; 40 ; 70$} \\
\hline Axial depth of cut $A_{p}[\mathrm{~mm}]$ & \multicolumn{2}{|c|}{0.05} \\
\hline Cutting fluid & \multicolumn{2}{|c|}{ Micromist } \\
\hline
\end{tabular}

After machining, a tool and machined channels were cleaned ultrasonically with isopropyl alcohol for 3-5 minutes and dried with pressurized air. Tool wear and build up edge (BUE) were either observed and measured on the Olympus STM6 at $0.1 \mu \mathrm{m}$ resolution, or observed with the JEOL 6400 electron microscope that integrated with an energy dispersive X-ray system. Surface finish along a milled groove was measured with a Zygo white light interferometer, which provided three dimensional surface profiles. Two different types of measurements were performed: (1) along the center line of the channel; and (2) at the side wall of the channel 60-70 $\mu \mathrm{m}$ away from center line. The average surface finish $\mathrm{Ra}$ along a line was obtained for all specimens along a line of
$0.9 \mathrm{~mm}$ long. The measurements were repeated in the different locations of the same channel 10 times and the average value of surface roughness was calculated.

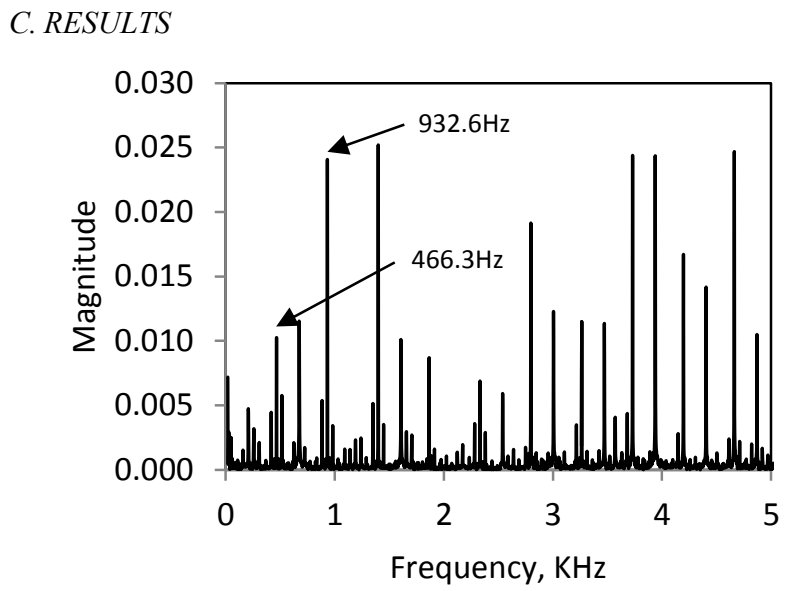

Fig. 3: Frequency spectrum of tool and spindle runout. Rotating spindle without machining, ball end mill $\phi 0.152 \mathrm{~mm}$, spindle speed 27238 rpm.

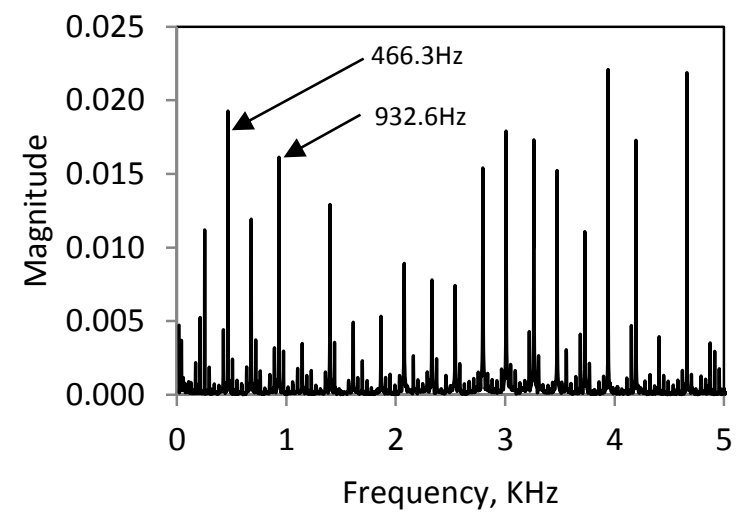

Fig. 4: Frequency spectrum of tool and spindle runout. Milling CP titanium, ball end mill $\phi 0.152 \mathrm{~mm}$, spindle speed $27238 \mathrm{rpm}$, feed rate $2.7 \mathrm{~mm} / \mathrm{min}$, depth of cut $38 \mu \mathrm{m}, M Q L$.

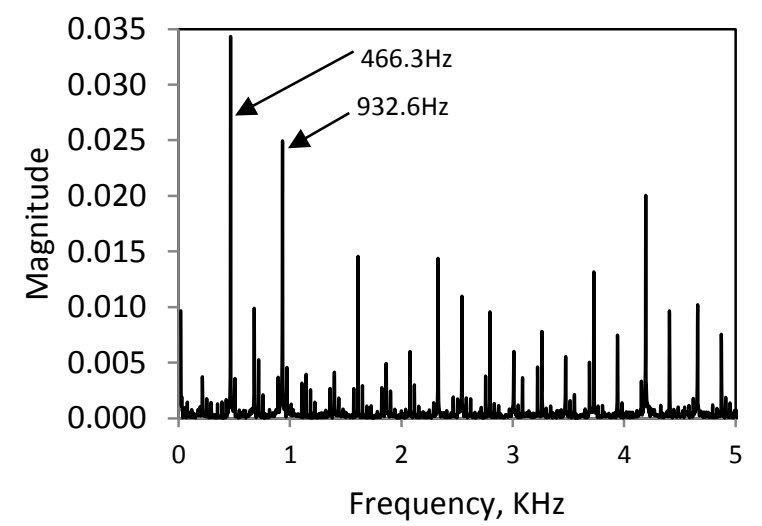

Fig. 5: Frequency spectrum of tool and spindle runout. Milling CP titanium, ball end mill $\phi 0.152 \mathrm{~mm}$, spindle speed $27238 \mathrm{rpm}$, feed rate $2.7 \mathrm{~mm} / \mathrm{min}$, depth of cut $76 \mu \mathrm{m}, \mathrm{MQL}$. 
Fast Fourier transform (FFT) plots, generated from laser displacement data, provide detailed frequency spectra and show the dynamics of milling system (Figs. 3-5). Two primary peaks on each FFT plot correspond to the spindle speed frequency of $932.6 \mathrm{~Hz}$ and the tooth passing frequency of $466.3 \mathrm{~Hz}$. Other peaks that appear on the plots could be due to harmonic vibration, or laser and MQL system noises, or result of the utilization of the data acquisition card at low sampling rate. It can be seen from the Fig. 3 that the spindle speed peak for the rotating spindle without machining corresponds to the runout of the spindle and tool combination. The amplitude of the tooth passing peak increases slightly while milling at $0.038 \mathrm{~mm}$ depth of cut (half of tool radius) compared to its amplitude for rotating of the spindle without machining (Figs. 3 and 4), but increases significantly when depth of cut is equal to the tool radius of $0.076 \mathrm{~mm}$ (Fig. 5). The spindle speed peak amplitude dominates others in free rotation without milling, but reduces when a tool is engaged during machining. Tool deflection, due to cyclic milling, forces in an interrupted milling operation, therefore, is the primary concern for this machining system. Depths of cut lower than half of the tool radii are subsequently utilized for all machining experiments.

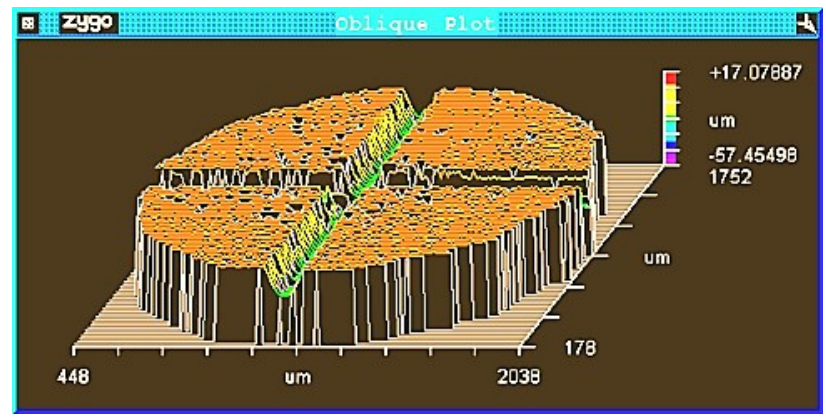

(a)

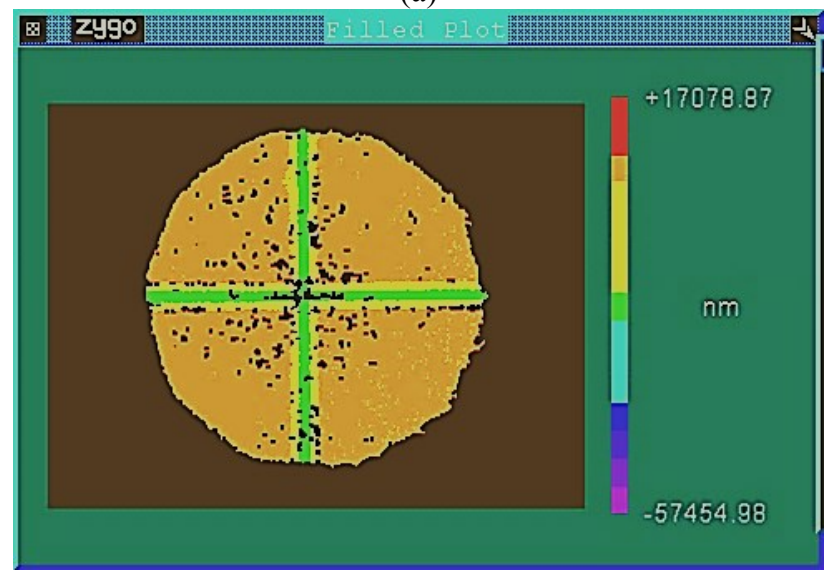

(b)

Fig. 6: Topographic profile of milled microchannel: (a) oblique view and (b) top view for roughness measurement. 304 stainless steel, coated $\phi 0.198 \mathrm{~mm}$ ball end $\mathrm{mill}, 24 \mathrm{~m} / \mathrm{min}, 0.05 \mu \mathrm{m} / \mathrm{tooth}$, MQL, average Ra $=0.18 \mu \mathrm{m}$.

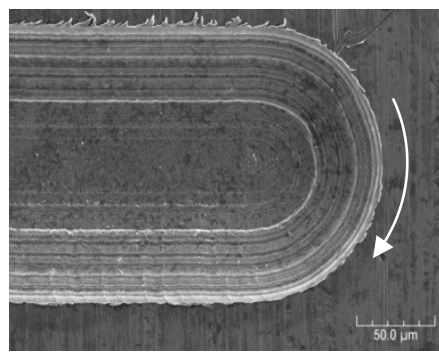

(a)

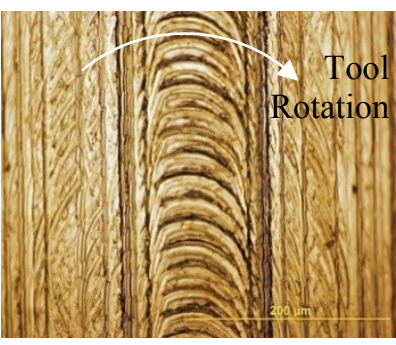

(b)
Fig. 7: (a) SEM picture of a milled microchannel. 304 stainless steel, coated $\phi 0.198 \mathrm{~mm}$ ball end $\mathrm{mill}, 24 \mathrm{~m} / \mathrm{min}, 0.1 \mu \mathrm{m} / \mathrm{tooth}$, MQL; and (b) Optical image of a milled mesochannel. 6061-T6 aluminum, uncoated $\phi 3.175 \mathrm{~mm}$ ball end mill, $60 \mathrm{~m} / \mathrm{min}, 5$ $\mu \mathrm{m} /$ tooth, MQL.

Fig. 6 shows a typical surface profile of milled microchannel. Surface finish data along a line of $0.9 \mathrm{~mm}$ along a channel axis are tabulated in Table 4. Surface finish values measuring along the center line of a milled channel are higher than those measuring away from it. Figures $7 \mathrm{a}$ and $7 \mathrm{~b}$ show the chip load distance (feed mark) at the channel center, and scratching parallel lines away from the center due to missing WC grains on the tool cutting edges as seen with high magnification scanning electron microscopic examination. An uncoated tool performs like coated tool when new, but is quickly deteriorated due to tool wear and forming of BUE. Figures 8 and 9 are SEM pictures of uncoated ball end mills after machining a microchannel of $24 \mathrm{~mm}$ length on stainless steel. Build-up-edge forms and abrasive wear progresses on both tools. Figure 10 shows SEM images of coated ball end mill after machining of $24 \mathrm{~mm}$ of stainless steel and $8 \mathrm{~mm}$ of NiTi alloy. Although no abrasive tool wear is seen, its coating layer is chipped off along the cutting edges. No significant BUE is seen on coated tool, but sizable BUEs are obvious at the edges of uncoated tools. Such BUE increases effective cutting edge radius, generates more burrs, work-hardens the machined subsurface, and worsens the surface finish. Lack of BUE on coated tool also results in better surface finish of micromilled channels on 304/316L stainless steels, NiTi alloy, A36 low carbon steel and 6061-T6 aluminum (Fig. 11). This is in agreement with another experimental study that found micromilling $\mathrm{Ti}-6 \mathrm{Al}-4 \mathrm{~V}$ in dry condition promotes BUE and worsens surface finish [10].

Milling direction affects the surface integrity of a microchannel. Referring to Fig. 2, a cutter is programmed to mill a channel from points 1-2 then 3-4. The combination of tool rotation direction and tool feed direction provides down milling on the right of moving tool and up milling on its left. Down milling generates fewer burrs as compared to up milling as seen in Figs. 11a and 11b. The excessive and non-uniform burrs pose a challenging task to remove them after micromilling. 
Table 4: Resulted surface finish.

\begin{tabular}{|c|c|c|c|c|c|}
\hline Material & Tool & $\begin{array}{c}V \\
{[\mathrm{~m} /} \\
\min ]\end{array}$ & $\begin{array}{c}f_{t} \\
{[\mu \mathrm{m} /} \\
\text { tooth] }\end{array}$ & $\begin{array}{c}R_{a} \\
\text { Center } \\
{[\mu \mathrm{m}]}\end{array}$ & $\begin{array}{c}R_{a} \\
\text { Side } \\
\text { wall } \\
{[\mu \mathrm{m}]}\end{array}$ \\
\hline \multirow{8}{*}{304} & \multirow{4}{*}{$\begin{array}{c}\text { Uncoated } \\
\varnothing 0.152 \\
\mathrm{~mm}\end{array}$} & \multirow{4}{*}{24} & 0.05 & 0.16 & - \\
\hline & & & 0.1 & 0.32 & - \\
\hline & & & 0.2 & 0.25 & - \\
\hline & & & 0.3 & 0.47 & - \\
\hline & \multirow{4}{*}{$\begin{array}{c}\text { AlTiN } \\
\text { Coating } \\
\varnothing 0.198 \\
\mathrm{~mm}\end{array}$} & \multirow{4}{*}{24} & 0.05 & 0.18 & - \\
\hline & & & 0.1 & 0.25 & - \\
\hline & & & 0.2 & 0.20 & - \\
\hline & & & 0.3 & 0.35 & - \\
\hline \multirow{8}{*}{$316 \mathrm{~L}$} & \multirow{4}{*}{$\begin{array}{c}\text { Uncoated } \\
\varnothing 0.152 \\
\text { mm }\end{array}$} & \multirow{4}{*}{24} & 0.05 & 0.39 & - \\
\hline & & & 0.1 & 0.68 & - \\
\hline & & & 0.2 & 1.32 & - \\
\hline & & & 0.3 & 1.40 & - \\
\hline & \multirow{4}{*}{$\begin{array}{c}\text { AlTiN } \\
\text { Coating } \\
\varnothing 0.198 \\
\text { mm }\end{array}$} & \multirow{4}{*}{24} & 0.05 & 0.39 & - \\
\hline & & & 0.1 & 0.26 & - \\
\hline & & & 0.2 & 0.40 & - \\
\hline & & & 0.3 & 0.38 & - \\
\hline \multirow{4}{*}{ NiTi } & \multirow{4}{*}{$\begin{array}{c}\text { AlTiN } \\
\text { Coating } \\
\varnothing 0.198 \\
\text { mm }\end{array}$} & \multirow{4}{*}{24} & 0.05 & 0.10 & - \\
\hline & & & 0.1 & 0.12 & - \\
\hline & & & 0.2 & 0.24 & - \\
\hline & & & 0.3 & 0.26 & - \\
\hline \multirow{14}{*}{ 6061-T6 } & \multirow{7}{*}{$\begin{array}{c}\text { Uncoated } \\
\varnothing 3.175 \\
\text { mm }\end{array}$} & \multirow{7}{*}{60} & 5 & 0.33 & 0.18 \\
\hline & & & 10 & 0.33 & 0.24 \\
\hline & & & 20 & 0.37 & 0.28 \\
\hline & & & 30 & 0.38 & 0.49 \\
\hline & & & 50 & 1.63 & 0.60 \\
\hline & & & 80 & 2.91 & 1.35 \\
\hline & & & 100 & 4.34 & 1.73 \\
\hline & \multirow{7}{*}{$\begin{array}{c}\text { AlTiN } \\
\text { Coating } \\
\varnothing 3.175 \\
\text { mm }\end{array}$} & \multirow{7}{*}{60} & 5 & 0.31 & 0.25 \\
\hline & & & 10 & 0.37 & 0.37 \\
\hline & & & 20 & 0.75 & 0.45 \\
\hline & & & 30 & 1.08 & 0.79 \\
\hline & & & 50 & 1.48 & 1.10 \\
\hline & & & 80 & 3.34 & 1.64 \\
\hline & & & 100 & 4.46 & 2.07 \\
\hline \multirow{8}{*}{ A36 } & \multirow{4}{*}{$\begin{array}{c}\text { Uncoated } \\
\varnothing 3.175 \\
\text { mm }\end{array}$} & \multirow{4}{*}{30} & 5 & 0.50 & 0.22 \\
\hline & & & 15 & 0.41 & 0.32 \\
\hline & & & 40 & 0.98 & 0.64 \\
\hline & & & 70 & 2.33 & 1.63 \\
\hline & \multirow{4}{*}{$\begin{array}{c}\text { AlTiN } \\
\text { Coating } \\
\varnothing 3.175 \\
\text { mm }\end{array}$} & \multirow{4}{*}{30} & 5 & 0.60 & 0.36 \\
\hline & & & 15 & 0.53 & 0.37 \\
\hline & & & 40 & 1.44 & 1.26 \\
\hline & & & 70 & 2.63 & 1.79 \\
\hline
\end{tabular}

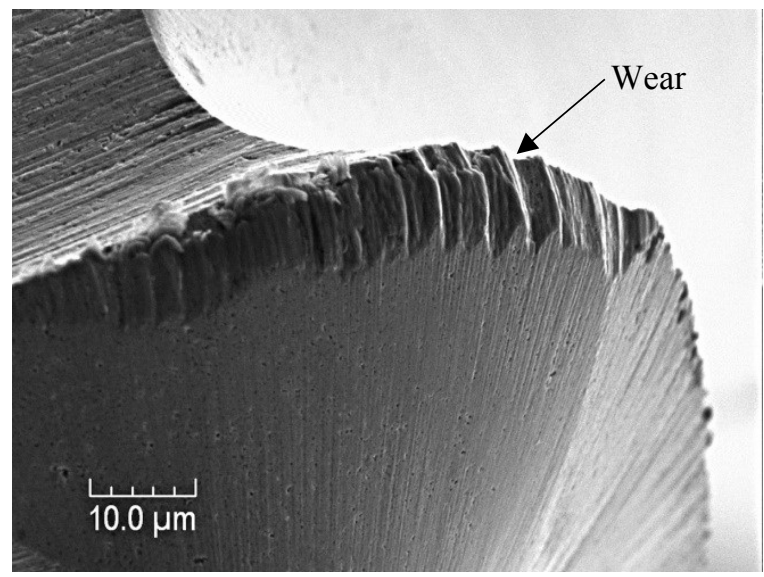

Fig. 8: Significant abrasive wear of uncoated $\phi 0.152 \mathrm{~mm}$ ball end mill. Micromilling at $24 \mathrm{~m} / \mathrm{min}, 0.1 \mu \mathrm{m} /$ tooth, $M Q L$, after machining $12 \mathrm{~mm}$ of 304 stainless steel and $12 \mathrm{~mm}$ of $316 \mathrm{~L}$ stainless steel.

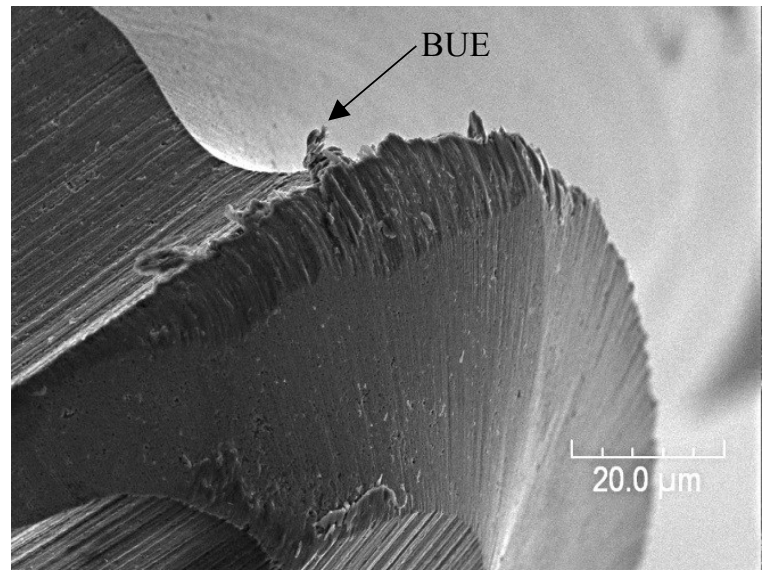

Fig. 9: Built-up edges of uncoated $\phi 0.152 \mathrm{~mm}$ ball end mill. Micromilling at $24 \mathrm{~m} / \mathrm{min}, 0.2 \mu \mathrm{m} /$ tooth, MQL, after machining 12 mm of 304 stainless steel and $12 \mathrm{~mm}$ of $316 \mathrm{~L}$ stainless steel.

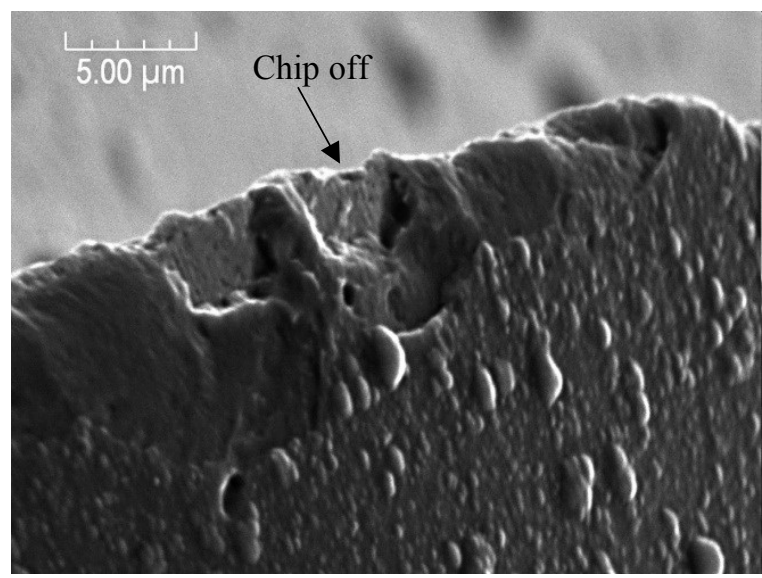

Fig. 10: Chipping of AlTiN coating layer on a coated $\phi 0.198 \mathrm{~mm}$ ball end mill. Micromilling at $24 \mathrm{~m} / \mathrm{min}, 0.1 \mu \mathrm{m} / \mathrm{tooth}, \mathrm{MQL}$, after $12 \mathrm{~mm}$ of 304 stainless steel, $12 \mathrm{~mm}$ of $316 \mathrm{~L}$ stainless steel, and 8 mm of NiTi. 


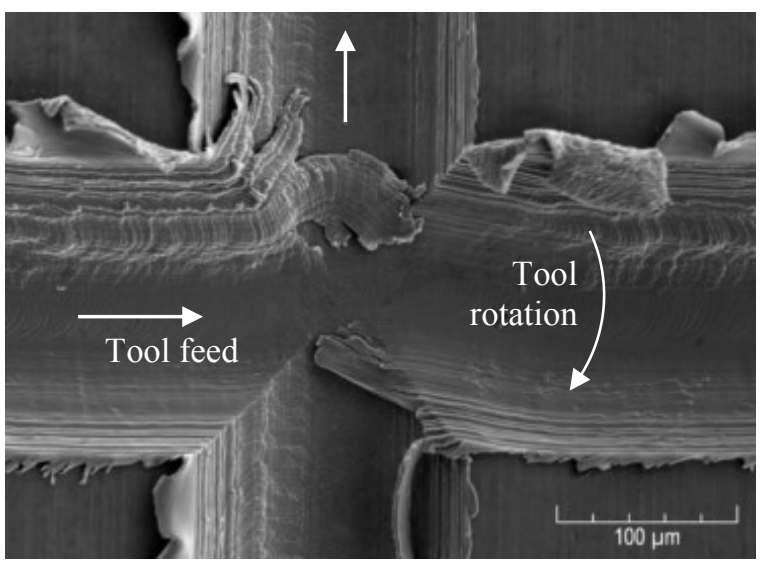

(a)

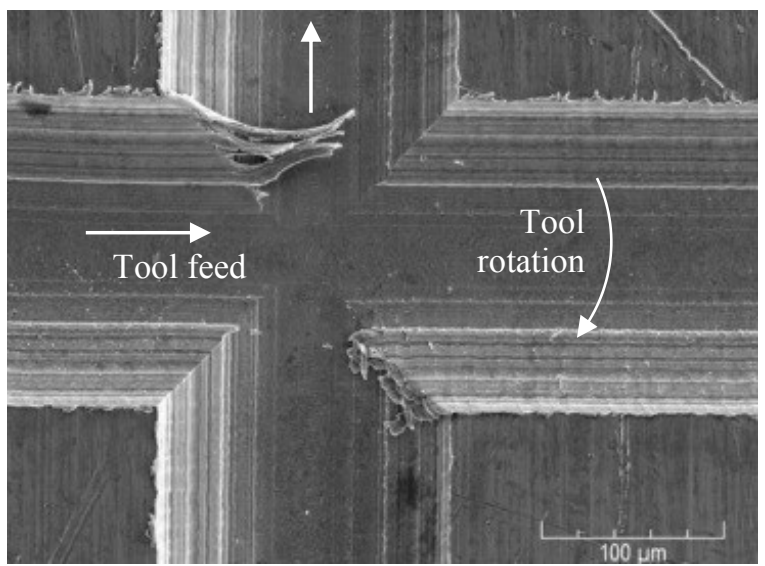

(b)

Fig. 11: Effect of tool coating on resulting burrs: (a) uncoated $\phi 0.152 \mathrm{~mm}$ tool, milling 304 stainless steel, $24 \mathrm{~m} / \mathrm{min}, 0.1$ um/tooth, MQL; (b) AlTiN coated $\phi 0.198 \mathrm{~mm}$ tool, milling 304 stainless steel, $24 \mathrm{~m} / \mathrm{min}, 0.1 \mu \mathrm{m} / \mathrm{tooth}, M Q L$.

Other milling parameters also affect the surface finish. Varying feed rate (or chip load) significantly changes the surface finish. The theoretical surface finish in conventional ball end milling is given by [12]:

$$
R_{a}=0.2568 \frac{f_{t}^{2}}{D}
$$

To investigate the surface finish with different tool sizes, equation (1) can be modified by multiply the tool diameter on both sides to obtain:

$$
D \cdot R_{a}=0.2568 f_{t}^{2}
$$

Where

$$
\begin{aligned}
R_{a} & : \text { average surface finish } \\
f_{t} & : \text { chip load } \\
D & : \text { diameter of ball-end milling tool }
\end{aligned}
$$

A plot of the product $D . R_{a}$ against the chip load $f_{t}$, therefore, should be a straight line on log-log scale graph. Experimental data, however, would fit the following empirical equation:

$$
D \cdot R_{a}=245.3 f_{t}^{0.7}
$$

Although equation (2) could predict surface roughness in macro and meso-scale ball-end milling, extending its range to micromilling would be erroneous due to size effect, tool edge sharpness, grain orientation, smearing of chips, and formation of BUE. In practice, it is difficult to quantify surface finish on the wall or bottom of a microchannel. Atomic force microscopy or scanning tunneling microscopy can be used effectively on a flat surface, these techniques are not effective for a deep microchannel. Optical technique such as interferometer is used in this study since the milled surface is reflective to form recognizable fringes.

Fig. 12 plots surface finish data for different materials and tool sizes in this study. The empirical equation (3) is derived from line fitting of experimental data while equation (2) predicts wrong data when chip load is below $100 \mu \mathrm{m}$.

The experimental data and theoretical prediction show a smoother surface should be obtainable with low chip load; however, this contradicts with another study that found feed rate, therefore chip load, does not affect surface finish [9]. It is postulated that a wrong combination of large tool edge radius and shallow depth of cut could smear the surface and does not truly reflect the contribution of chip load.

Flat plates with multiple micromilled channels can be polished to remove burrs and enhance surface quality. Electrochemical polishing is an effective finishing technique to remove burrs and work hardened layer while polishing a machined surface. The combination of these hybrid processes can produce microchannels with $<100 \mathrm{~nm} \mathrm{R}_{\mathrm{a}}$ finish on polycrystalline materials (Fig. 13)

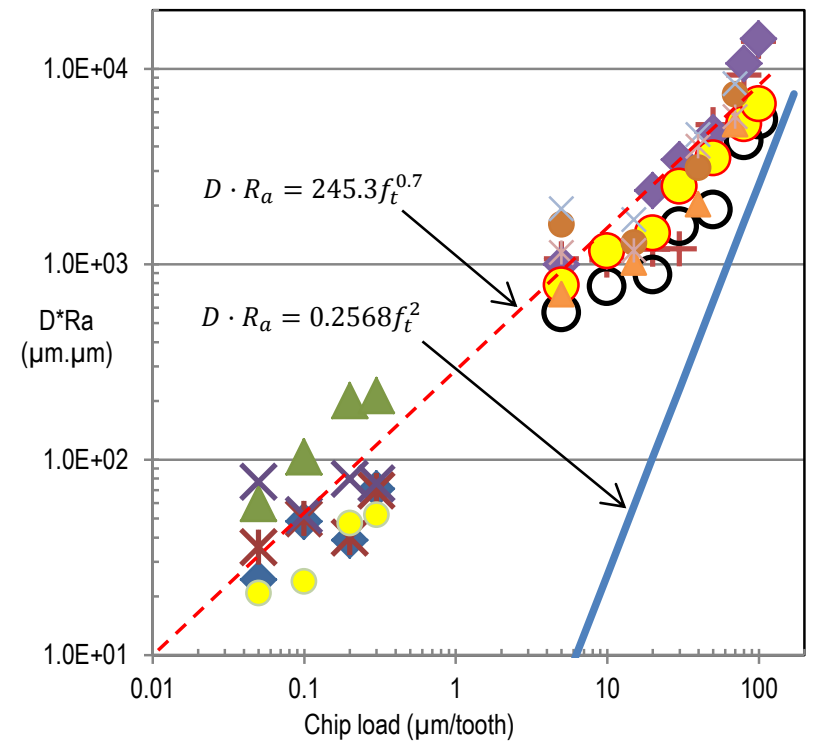

Fig. 12: Surface finish at bottom of milled microchannels. Ball-end tools $\phi$ 0.152-3.175 mm, milling on 6061-T6, A36 steel, NiTi, 304/316L stainless steel, MQL. 
Legends for data in Fig. 12.

-Center of the slot; uncoated tool d0.152 $\mathrm{mm} ; \mathrm{V}=24 \mathrm{~m} / \mathrm{min}$; $A p=0.03 \mathrm{~mm} ;$ after $12 \mathrm{~mm}$ of $304 \mathrm{SS}$

*Center of the slot; coated tool d0.198 $\mathrm{mm} ; \mathrm{V}=24 \mathrm{~m} / \mathrm{min}$; $A p=0.03 \mathrm{~mm}$; after $12 \mathrm{~mm}$ of $304 \mathrm{SS}$

$\Delta$ Center of the slot; uncoated tool $\mathrm{d} 0.152 \mathrm{~mm} ; \mathrm{V}=24 \mathrm{~m} / \mathrm{min}$; $A p=0.03 \mathrm{~mm}$; after $12 \mathrm{~mm}$ of $304 \mathrm{SS}$ and $12 \mathrm{~mm}$ of $316 \mathrm{~L} \mathrm{SS}$

$\times$ Center of the slot; coated tool d0.198mm;V=24m/min; $A p=0.03 \mathrm{~mm}$; after $12 \mathrm{~mm}$ of $304 \mathrm{SS}$ and $12 \mathrm{~mm}$ of $316 \mathrm{~L} \mathrm{SS}$

+Center of the slot; uncoated tool $\mathrm{d} 3.175 \mathrm{~mm} ; \mathrm{V}=60 \mathrm{~m} / \mathrm{min}$; $A p=0.1 \mathrm{~mm}$; after $10 \mathrm{~mm}$ of $6061-\mathrm{T} 6$

OSide wall of the slot? uncoated tool $\mathrm{d} 3.175 \mathrm{~mm} ; \mathrm{V}=60 \mathrm{~m} / \mathrm{min}$; $A p=0.1 \mathrm{~mm}$; after $10 \mathrm{~mm}$ of $6061-\mathrm{T} 6$

$\checkmark$ Center of the slot; coated tool $\mathrm{d} 3.175 \mathrm{~mm} ; \mathrm{V}=60 \mathrm{~m} / \mathrm{min}$; Ap $=0.1 \mathrm{~mm}$; after $10 \mathrm{~mm}$ of $6061-\mathrm{T} 6$

OSide wall of the slot coated tool $\mathrm{d} 3.175 \mathrm{~mm} ; \mathrm{V}=60 \mathrm{~m} / \mathrm{min}$; Ap $=0.1 \mathrm{~mm}$; after $10 \mathrm{~mm}$ of $6061-\mathrm{T} 6$

- Center of the slot; uncoated tool $\mathrm{d} 3.175 \mathrm{~mm} ; \mathrm{V}=30 \mathrm{~m} / \mathrm{min}$; $A p=0.05 \mathrm{~mm}$; after $20 \mathrm{~mm}$ of $\mathrm{A} 36$ low carbon steel

$\Delta$ Side wall of the slot; uncoated tool $\mathrm{d} 3.175 \mathrm{~mm} ; \mathrm{V}=30 \mathrm{~m} / \mathrm{min}$ $A p=0.05 \mathrm{~mm}$; after $20 \mathrm{~mm}$ of $\mathrm{A} 36$ low carbon steel

Center of the slot; coated tool $\mathrm{d} 3.175 \mathrm{~mm} ; \mathrm{V}=30 \mathrm{~m} / \mathrm{min}$; $A p=0.05 \mathrm{~mm}$; after $20 \mathrm{~mm}$ of $\mathrm{A} 36$ low carbon steel

$X$ Side wall of the slot coated tool $\mathrm{d} 3.175 \mathrm{~mm} ; \mathrm{V}=30 \mathrm{~m} / \mathrm{min}$; $A p=0.05 \mathrm{~mm}$; after $20 \mathrm{~mm}$ of $\mathrm{A} 36$ low carbon steel

Center of the slot; coated tool $\mathrm{d} 0.198 \mathrm{~mm} ; \mathrm{V}=24 \mathrm{~m} / \mathrm{min}$; $A p=0.03 \mathrm{~mm}$; after $12 \mathrm{~mm}$ of $304 \mathrm{SS}, 12 \mathrm{~mm}$ of $316 \mathrm{~L} \mathrm{SS}$, and $8 \mathrm{~mm}$ of $\mathrm{NiTi}$

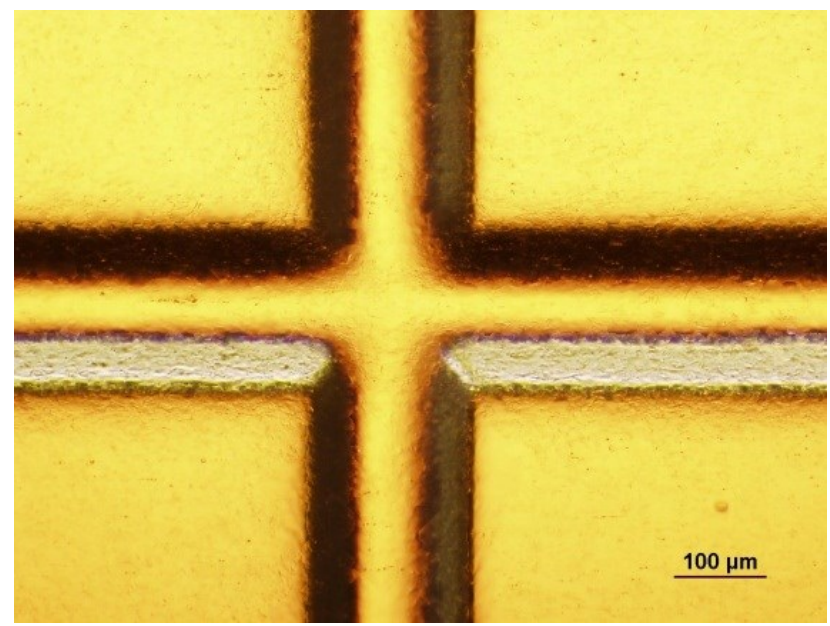

Fig. 13: Micromilling following by electrochemical polishing of 304 stainless steel microchannels.

\section{CONCLUSION}

Fabrication of microchannels on biocompatible alloys using micromilling and electrochemical polishing is presented. This study shows:

1) Build-up-edges worsen surface finish and increases burr formation. Formation of BUEs and wear of the tool are minimized with properly coated tool and micromilling in minimum quantity lubrication.

2) The theoretical surface finish model is applicable for macro/meso scale milling. Extrapolation the model to micro-scale ball milling is erroneous due to size effect, tool edge sharpness, smearing of chips, and formation of BUE. Empirical model shows the dependence of surface finish and chip load.

3) Down milling produces fewer burrs than up milling. Ball-end milled microchannels can be effectively polished by electrochemical polishing technique.

4) Hybrid micromilling and polishing allow fabrication of microchannels on polycrystalline stainless steel, Nitinol and titanium with surface finish consistently less than $100 \mathrm{~nm} \mathrm{R}_{\mathrm{a}}$.

\section{ACKNOWLEDGEMENT}

The authors would like to thank Professor Manny Soriaga, Mr. Dakota Brock, Mr. Xiao Han, and Mr. Brennon Sessions of Chemistry Department at Texas A\&M University for their kind assistance.

Generous support from Agilent, Haas Automation, Unist, Performance Micro Tools, and Swiss-Tek Coatings is much appreciated.

\section{REFERENCES}

[1] A. Dhanorker, T. Özel, "An experimental and Modeling study on meso/micro end milling process," International Manufacturing Science and Engineering Conference: 2006, Paper No. 21127.

[2] D. Dornfeld, S. Min, Y. Takeuchi, "Recent Advances in Mechanical Micromachining," CIRP Annals - Manufacturing technology, 2006; 55: 745-768.

[3] K. Iwata, T. Moriwaka, K. Okuda, "Ultra-high precision diamond cutting of copper," Memoirs of faculty of engineering, Kobe University, 1984; 31: 93-102.

[4] J. Chae, S.S. Park, T. Freiheit, "Investigation of micro-cutting operations," International Journal of Machine Tools \& Manufacture, 2006; 46: 313-332.

[5] H. Weule, V. Huntrup, H. Tritschler, "Micro-cutting of steel to meet new requirements in miniaturization," Annals of CIRP, 2001; 50: 6164.

[6] T. Dow, E. Miller, K. Garrard, "Tool force and deflection compensation for small milling tools," Precision Engineering, 2004; 28: 31-45.

[7] M. Vogler, R. Devor, S. Kapoor, "On the modeling and analysis of machining performance in micro end milling. Part II: Cutting force prediction," Journal of Manufacturing Science and Engineering, 2004; 126 (4): 685-705.

[8] S. Shimada, N. Ikawa, H. Tanaka, G. Ohmori, J. Uchikoshi, H. Yoshinaga. "Feasibility study on ultimate accuracy in micro cutting using molecular dynamics simulation," CIRP Annals, 1993; 42/1: 91-94. 
8th ICOMM, March 25-28, 2013

[9] H. Shizuka, K. Okuda, M. Nunobiki, Y. Inada, "Study on Surface Roughness in Micro End Milling of Mold Material," Advanced Material Research, 2011; 325: 594-599.

[10] K. Tsuda, K. Okuda, H. Shizuka, M. Nunobiki, "A Study of the Micro-end Milling of Titanium Alloy," Advanced Material Research, 2011; 325: 588-593.

[11] T. Ozel, T. Thepsonthi, D. Ulutan, B. Kaftanoglu, "Experiments and Finite Element Simulations on Micromilling of Ti-6Al-4V Alloy with Uncoated and CBN Coated Micro Tools," CIRP AnnalsManufacturing Technology, 2011; 60: 85-88.

[12] G. Boothroyd and W. Knight, "Fundamentals of Machining and Machine Tools," Marcel Dekker, CRC Press: 1989. 